1876 benannte A. Kerner (Oesterr. botan. Zeitschr. S. 112) ein Epilobium (E. alsinefolium $\times$ tetragonum) $E$. Winkleri.

Allmälig hatte er sein Herbarium zu einem europäischen erweitert, das weit bedeutender als das verbrannte geworden war.

Als ihn das Alter zwang, seine Stellung als Fabriksdirector aufzugeben, blieb er doch in Giesmannsdorf auf des Ministers Friedenthal ausdrücklichen Wunsch, der ihm neben der Pension noch eine kleine Villa mit daran stossendem Garten zur Benützung überliess. Hier richtete sich der Verstorbene bald eine AlpenpflanzenAnlage ein, die er mit grosser Liebe pflegte.

Weitere Reisen wurden nun nicht mehr unternommen und begnügte sich der Verstorbene mit kleineren Ausflügen nach den schlesischen Gebirgen, die er jeden Sommer bis zu seinem Tode unternahm.

Ueber sein Herbarium glanbte er noch bei Lebzeiten so verfügen zu müssen, dass es der wissenschaftlichen Benützung erhalten blieb. Er machte es daher im Jahre 1888 dem botanischen Garten seiner Vaterstadt Breslau zum Geschenke, in dessen Sammlungen es nummehr aufgenommen ist.

Während seines letzten Sommer-Aufenthaltes in Krummhübel zeigten sich bereits die Anzeichen eines bedenklichen Nierenleidens, dem er am 21. December 1889 in Görlitz erlag.

In ihm ist ein Mann dahingegangen, der unserer Wissenschaft stets mit reinster Liebe und Aufopferung anhing und sie stets förderte, wo sich ihm nur die Gelegenheit bot.

\title{
Erwiderung,
}

Meine Arbeiten über den Polymorphismus der Algen haben H. Zukal zweimal ${ }^{1}$ ) veranlasst, mir einen, wie ich glaube, unverdienten Vorwurf zu machen, auf den ich aus Gründen, die ich hier nicht anführen will, nicht sofort geantwortet habe.

Zukal's Verdienste um die von mir, sowie von vielen Anderen vor und nach mir vertheidigte Lehre vom Polymorphismus der Algen, welche man von gewisser Seite noch immer zu bemakeln sucht, habe ich nicht blos gleich in meiner ersten vorläufigen Mittheilung, wie Zukal selbst anerkannt hat ${ }^{2}$ ), nicht verschwiegen, sondern sie auch in meinem Hauptwerke "Physiologische und algologische Studien" offen mit folgenden Worten anerkannt: "Durch die neulich von $\mathrm{Z}$ opf etc. Zukal u. A. gelieferten Nachweise über den Polymorphismus der (yanophyceen"s) u. s. w.

1) „Oesterr. botan. Zeitschr.“ Bd. 38, S. 99 und Bd. 39, S. 350 .

2) A. a. O. S. 98 .

3) "Physiologische und algologische Studien“, S. 56. 
Dass ich vou dem kurzefassten Aufsatze Zukal's: "Bacterien - als Ablömmlinge einer Alge" keine weitere Erwähnung in meinen Abhandlungen über den Polymorphismus der blangrünen Algeu gethan habe, geschah hauptsächlich aus dem Grunde, weil Zukal von einem anderen Standpunkte als ich, über die Metamorphose des Scytonema Hofmanni $\boldsymbol{A g}$. abgehandelt hat.

Auf den Werth der von Zukal über den Polymorphismus der Cyanophyceen publicirten Beobachtungen etc. will ich hier, ans den von diesem Forscher (a. a. 0. Jahrg. 1888, S. 98) angeführten Gründen; nicht näher eingehen und erwähne hier blos nebenbei, dass der von Zukal in dieser Zeitschrift, Bd. 39, Tab. II, Fig. 5 abgebildete "Scytonema-Ast, welcher sich in ein Nostoc-Individuum verwandelt" dem von Borzi (Note alla morfologia a biologia delle alghe ficocromacee, 1882, Tab. 16, Fig. 9) abgebildeten Sacconema rupestre nicht unähnlich sieht, was vielleicht Zukal entgangen ist.

Prof. Anton Hansgirg.

\section{Litteratur-Uebersicht. $\left.{ }^{\top}\right)$}

\section{December 1889.}

Beck G. R. v. Zur Pilzflora Nieder-Oesterreichs V. (Verh. d. zool.botan. Gesellsch. 1889, S. 593.) 8º 23 S. 1 Taf.

44 Arten neu für das Kronland - 9 Arten überhaupt neu: Clavaria sculpta, Sonntagsberg bei Rosenau (Zahlbruckner), *Hydnum velutipes; Rothgraben (Beck), *Polyporus bulbipes, Kampalpe (Beck), Hyyropolorus citrinocroceus, Kranichberg (Ganglbauer), $H$, rubescens, Kranjchberg (Ganglb.), $H$. miniaceus, Sonntagsberg (Zahlbr.), *Agaricus praenitens, Kranichberg (Ganglb.), ${ }^{*}$ A. Zahlbruckneri, Sonntagsberg (Zahlbr.), *A. alpicolus, Raxalpe (Beck). Die mit * bezeichneten Arten sind abgebildet. Im Uebrigen enthält die Abhandlung zahlreiche neue Standorte und Angaben über.Sporenmessungen.

Burgerstein A. Einige Beobachtungen an den Blüthen der Convolvulaceen. (Berichte d. Deutsch. botan. Gesellsch. 1889, Heft 9.) $8^{0} .6 \mathrm{~S}$.

Čelakovský L. Ueber die Cupula von Fagus u. Castanea. (Jahrbücher f. wissensch. Botanik 1889.) gr. 8". 35 S. 1 Taf.

Dörfler I. Formen und Monstrositäten von Equisetum Telmateja Ehrh. (Verh. d. zool.-botan. Gesellsch. XXXIX. Sitzungsber. S. 90.) $2 \mathrm{~s}$.

Vergl. d. Zeitschrift Nr. 1, S. 31.

1) Die "Litteratur-Uebersicht" strebt Vollständigkeit nur mit Rücksicht auf jene Abhandlungen an, die entweder in Oesterreich-Ungarn erscheinen oder sich auf die Flora dieses Gebietes direct oder indirect beziehen, ferner auf selbstständige Werke des Auslandes. Zur Erzielung thunlichster Vollständjgkeit werden die Herren Autoren und Verleger um Einsendung von neu erschienenen Arbeiten böflichst ersucht. Die Red. 